\title{
Estudo da prevalência de DORT's em motoristas de uma empresa de transporte público em Santarém-PA
}

\author{
Study of the prevalence of "DORT's" in drivers of a public transport company \\ in Santarém-PA
}

\begin{abstract}
Estudio de la prevalência de "DORT's" en conductores de una empresa de transporte público em Santarém-PA
\end{abstract}

Andria Catarina da Silva Rêgo ${ }^{1 *}$, Ingrid Mayara Sousa da Silva ${ }^{1}$, Suzane de Araújo Pantoja ${ }^{1}$, Marina Silva Nicolau Taketomi'.

\section{RESUMO}

Objetivo: Analisar a prevalência de doenças ocupacionais do transporte público em Santarém-PA. Métodos: O estudo apresenta caráter descritivo para investigar, observar, registrar, analisar e ordenar dados. A coleta de dados foi realizada através da aplicação de questionário com os motoristas de uma empresa de ônibus que atua na zona urbana da cidade de Santarém-PA, de ambos os sexos, com mais de seis meses de trabalho e que sejam voluntários da pesquisa, sendo excluídos os trabalhadores da zona rural, bem como aqueles que não quiseram participar de forma voluntária ou por motivo específico estejam afastados do trabalho. Resultados: Foram observados fatores contribuintes para 0 desenvolvimento de distúrbios osteomioarticulares, como a postura incorreta ao desenvolver as atividades, bem como a falta de realização de atividades físicas, onde tais fatores levaram a maioria dos entrevistados $(57,1 \%)$ a apresentar, desconforto físico, cansaço mental e dores nas costas, cabeça e lombar. Conclusão: É possível concluir que vários são os fatores capazes de ocasionar distúrbios osteomioarticulares nos motoristas de ônibus da cidade de Santarém-PA, destacando-se a inércia das empresas quanto à melhoria das condições de trabalho, bem como ao estímulo e conscientização da importância de atividades físicas.

Palavras-chave: Doença ocupacional, Osteomioarticular, Motorista.

\begin{abstract}
Objective: To analyze the prevalence of occupational diseases in public transport in Santarém-PA. Methods: The study has a descriptive character to investigate, observe, record, analyze and order data. Data collection was carried out through the application of a questionnaire with the drivers of a bus company that works in the urban area of the city of Santarém-PA, of both sexes, with more than six months of work and who are volunteers of the research, rural workers, as well as those who did not want to participate voluntarily or for specific reasons, are excluded from work. Results: Factors contributing to the development of musculoskeletal disorders were observed, such as incorrect posture when developing activities, as well as the lack of physical activity, where such factors led most of the interviewees (57.1\%) to experience discomfort physical, mental tiredness and back, head and lower back pain. Conclusion: It is possible to conclude that several factors are capable of causing musculoskeletal disorders in bus drivers in the city of Santarém-PA, highlighting the companies' inertia regarding the improvement of working conditions, as well as the encouragement and awareness of the importance of physical activities.
\end{abstract}

Key words: Occupational disease, Osteomioarticular, Driver.

${ }^{1}$ Instituto Esperança de Ensino Superior (IESPES), Santarém - PA. *E-mail: andria.catarinafisio@gmail.com 


\section{RESUMEN}

Objetivo: Analizar la prevalencia de enfermedades profesionales en el transporte público en Santarém-PA. Métodos: El estudio tiene un carácter descriptivo para investigar, observar, registrar, analizar y ordenar datos. La recogida de datos se realizó mediante la aplicación de un cuestionario a los conductores de una empresa de autobuses que trabaja en el casco urbano de la ciudad de Santarém-PA, de ambos sexos, con más de seis meses de trabajo y que son voluntarios de Los investigadores, los trabajadores rurales, así como aquellos que no quisieron participar voluntariamente o por razones específicas, están excluidos del trabajo. Resultados: Se observaron factores que contribuyeron al desarrollo de trastornos musculoesqueléticos, como la postura incorrecta al desarrollar actividades, así como la falta de actividad física, donde tales factores llevaron a la mayoría de los entrevistados $(57,1 \%)$ a experimentar malestar físico, cansancio mental y dolor de espalda, cabeza y lumbago. Conclusión: Es posible concluir que varios factores son capaces de provocar trastornos musculoesqueléticos en los conductores de autobús de la ciudad de Santarém-PA, destacando la inercia de las empresas en la mejora de las condiciones laborales, así como el estímulo y conciencia de la importancia de actividades físicas.

Palabras clave: Enfermedad profesional, Osteomioarticular, Conductor.

\section{INTRODUÇÃO}

Os Distúrbios Osteomusculares Relacionados com o Trabalho (DORT's) são consideradas lesões ou síndromes derivadas do serviço ocupacional. Não possui fator, causa ou público específico, podendo acometer qualquer funcionário, sendo capaz de abalar o aspecto físico e psicológico do indivíduo, ocasionando improdutividade e até mesmo afastamento do trabalho (RIBEIRO HP, 1999).

Os termos LER (Lesão por esforço repetitivo) e DORT's são comumente utilizadas para designar um acometimento ocorrido devido a uma atividade laboral, porém esses termos são amplos, e definem uma só patologia. No geral esses termos são utilizados quando surgem algias associadas as atividades laborais, que podem se intensificar devido à fatores ambientais (MORAES PWT e BASTOS, 2017). No Brasil, nos últimos anos as DORT's foram as principais causas de afastamento do trabalho (DOSEA GS, et al., 2016)

De forma geral, é comum associar as doenças ocupacionais a profissões com risco elevado ou evidente, como aquelas que exigem grande e constante esforço físico ou aquelas onde há exposição do trabalhador a algum tipo de substância tóxica, por exemplo. Na maioria dos ambientes de trabalho não é possível eliminar os riscos de doenças ocupacionais pela natureza das atividades exercidas. Dessa forma, as empresas têm como obrigação adotar medidas de proteção individuais e coletivas, como os Equipamento de proteção coletiva (EPC) e Equipamentos de proteção individual (EPI), no intuito de amenizar os impactos ocasionados pelos fatores de risco (HOFFMANN MH, 2003).

Como forma de amenizar as DORT's em motoristas de transporte coletivo, cujo trabalho exige movimentos repetitivos por longos períodos de tempo, é essencial que sejam desenvolvidas medidas preventivas que vão desde informativos acerca dos malefícios da jornada laboral de longo prazo, até tratamentos específicos de fortalecimento muscular e proteção da ergonomia (SOUZA LPE, 2017).

Segundo Medeiros UV e Segatto GG (2012), as mudanças no ambiente de trabalho nos últimos anos fazem com que os trabalhadores realizem cada vez menos atividades que exijam força, esse benefício foi alcançado através dos avanços tecnológicos no ambiente de trabalho, porém ao mesmo os trabalhadores passam a realizar mais atividades repetitivas e monótonas, que acarretam outras disfunções, pois sobrecarregam sempre um mesmo grupo muscular, ou exigem sobrecarga deste musculo para manutenção da postura estática.

Especificamente, quanto aos meios a serem adotados para amenizar os efeitos deletérios da atividade laboral, é possível destacar a prática de atividades físicas com ênfase ao condicionamento da musculatura que é mais acometida por conta do trabalho, como a região da lombar, braços, pernas e ombros. Ao contrário 
do que acontece em outras atividades profissionais onde há um relativo conforto como sistema de climatização de ar condicionado e tarefas menos cansativas, os motoristas de ônibus enfrentam uma realidade cujas tarefas devem ser realizadas sob condições de estresse, pressão psicológica e insalubridade física (SOUZA LPE, 2017).

Somados a esses fatores, a inadequação dos veículos como bancos em estado crítico de conservação ou fora dos padrões aconselháveis para manter a postura, câmbio e direção com pouca ergonomia e precária manutenção dificultando sua utilização com pássaro do tempo e até mesmo a falta de informação do motorista no que se refere aos cuidados necessários para manter uma postura adequada durante a jornada de trabalho são condições que contribuem para o surgimento de distúrbios osteomioarticulares nos indivíduos condutores de ônibus que foram entrevistados (HOFFMANN MH, 2003).

Diante do proposto, o presente estudo visa analisar a ocorrência dos fatores associados às doenças ocupacionais em motoristas de ônibus na cidade de Santarém-PA, pretende-se fornecer informações para a melhorias nos processos de produção dos trabalhadores, no sentido de conscientizar empregadores e empregados quanto à importância da tomada de cuidados para prevenir doenças ocupacionais contribuindo, assim, para a redução das mesmas nessa classe trabalhista da cidade de Santarém-PA.

\section{MÉTODOS}

O estudo apresentou caráter descritivo uma vez que investiga, observa, registra, analisa e ordena dados, sem manipulá-los, isto é, sem influência do pesquisador. Sendo caracterizado como uma pesquisa transversal e quantitativa (BORDALO AA, 2006; KNECHTEL MR, 2014).

No que se refere aos aspectos éticos, foram seguidas as indicações da Resolução 466/2012 do Conselho Nacional de Saúde (CNS), órgão regulador de pesquisas envolvendo seres humanos, sendo a pesquisa autorizada pela empresa responsável de transporte público da cidade de Santarém-PA e aprovada no Comitê de Ética e Pesquisa em seres humanos da UEPA, campos XII, com parecer número 4.082.631.

Posteriormente às aprovações necessárias, a coleta de dados foi realizada entre os meses de abril e julho de 2020 e foi realizada em uma sala reservada nas empresas privadas do setor de transporte público da cidade de Santarém-PA, nos motoristas que aceitaram participar voluntariamente da pesquisa, assinando o Termo de Consentimento Livre e Esclarecido (TCLE).

A amostra da pesquisa foi constituída por sete motoristas, onde todos os se enquadraram nos critérios de inclusão e exclusão pré-definidos, sendo todos do gênero masculino e naturais da cidade de Santarém-PA. É necessário ressaltar que não houve perdas ou extravios quanto às informações coletadas.

Para participação pesquisa, aos participantes foram esclarecidos sobre os objetivos e procedimentos do estudo, seguido pela assinatura do TCLE. Como forma de resguardar a lisura dos resultados, as perguntas foram aplicadas de forma individual, para evitar possíveis constrangimentos e desconfortos tanto com relação aos demais colaboradores e/ou supervisores da empresa, quanto para proteger a identidade do entrevistado.

Por sua vez, os dados foram elencados em fichas elaboradas pelas autoras em forma de questionário, contendo itens que identifiquem o indivíduo entrevistado, além da data de coleta, idade, gênero, diagnóstico, causa e data de admissão. Foram excluídos da pesquisa os trabalhadores da zona rural, os analfabetos, os que não quiseram participar da pesquisa e todos aqueles afastados do trabalho durante o período de levantamento de dados.

\section{RESULTADOS}

A amostra foi composta por 7 (sete) participantes, na Tabela 1 é possível observar à distribuição das características quanto ao tempo de atuação na área, o gênero do entrevistado, se exerce ou já exerceu outras funções na empresa, a presença de desconforto físico e cansaço mental na rotina laboral, além do tempo de atuação como motorista em anos, na cidade de Santarém-PA: 
Tabela 1 - Caracterização dos motoristas de ônibus da cidade de Santarém-PA, N=7.

\begin{tabular}{lll}
\hline Variável & N & $\%$ \\
\hline Sexo & & \\
\hline Masculino & 7 & $100 \%$ \\
\hline Idade & 3 & \\
\hline $18-50$ & 4 & $60 \%$ \\
$51-60$ & & \\
\hline Outras funções na empresa & 3 & $42,90 \%$ \\
\hline Sim (mecânico, borracheiro) & 4 & $57,10 \%$ \\
\hline Não & & \\
\hline Cansaço físico e mental & 5 & $71,40 \%$ \\
\hline Sim (costas, lombar e cabeça) & 2 & $28,60 \%$ \\
Não & & \\
\hline Tempo de trabalho (anos) & 2 & $28,60 \%$ \\
\hline $4-6$ & 1 & $14,30 \%$ \\
$7-9$ & 2 & $28,60 \%$ \\
$10-15$ & 2 & $28,60 \%$ \\
\hline 15 & &
\end{tabular}

Fonte: Rêgo ACS, et al., 2021.

Como verificado na Tabela 1, todos os indivíduos são do sexo masculino, com idades que variam entre dezoito e sessenta anos, com tempo de trabalho não menor que quatro anos, sendo que a grande maioria $(71,40 \%)$ apresenta cansaço físico e mental com dores que irradiam para a região da cabeça, das costas e da lombar.

No que se refere às características laborais dos entrevistados, foi possível constatar que todos trabalham em média, 7 horas e 11 minutos diariamente, com pausas intrajornada que duram, em média, vinte e três minutos. Também foi possível constatar que $42,9 \%$ da amostra, ou seja, 3 (três) participantes, já exerceram outro tipo de função na empresa.

Quanto ao turno escolhido para exercer o trabalho, os entrevistados, em sua totalidade, optaram pelo turno matutino. A escolha também foi unânime no que se refere à afirmação de não realizar atividade laboral diversa de condução de ônibus. Também foi unânime a afirmativa de não realização de exercícios físicos por iniciativa da empresa. Desses, $71,4 \%$ afirmaram não realizar nenhum tipo de atividade física e $57,1 \%$ afirmaram apresentar, às vezes, uma postura correta no desempenho de suas funções.

Ainda de acordo com a Tabela $171,40 \%$ relataram sentir um desconforto ou cansaço mental desempenhando sua função, dentre eles, dor nas costas, na cabeça e na lombar, o que pode ser justificado pelo alto índice de sedentarismo na amostra, uma vez que $71,4 \%$ dos entrevistados não realizam nenhuma atividade física fora do ambiente ocupacional.

A Tabela 2, por sua vez, traz a distribuição das características quanto à percepção da temperatura e de ruídos no interior do ónibus, a sensação de vibração do corpo do próprio motorista, a presença de uma postura correta no desempenho das funções laborais, bem como a preocupação do entrevistado em capacitar o próprio condicionamento físico como forma de reduzir os impactos das doenças ocupacionais, cuja resposta negativa foi unânime. 
Tabela 2 - Características percebidas pelos motoristas de ônibus na cidade de Santarém-PA, N=7.

\begin{tabular}{llc}
\hline Características & N & $\%$ \\
\hline Percepção de temperatura & & \\
\hline Tolerável & 2 & $28,60 \%$ \\
Suportável & 3 & $42,90 \%$ \\
Sem queixas & 1 & $14,30 \%$ \\
Intolerável & 1 & $14,30 \%$ \\
\hline Percepção de ruídos & & \\
\hline Bom & 2 & $28,60 \%$ \\
Regular & 2 & $28,60 \%$ \\
Ruim & 2 & $28,60 \%$ \\
Muito ruim & 1 & $14,30 \%$ \\
\hline Sensação de vibração & & $14,30 \%$ \\
\hline Sempre & 1 & $14,30 \%$ \\
Quase sempre & 1 & $57,10 \%$ \\
Raramente & 4 & $14,30 \%$ \\
Nunca & 1 & \\
\hline Postura correta & & - \\
\hline Nunca & - & $57,10 \%$ \\
Às vezes & 4 & $42,90 \%$ \\
Sempre & 3 & \\
\hline Prática de exercício físico & & \\
\hline Sim & - & \\
Não & 7 & \\
\hline Fon & & \\
\hline Rego ACS, et al., & & \\
\hline
\end{tabular}

Fonte: Rêgo ACS, et al., 2021.

Por sua vez, a Tabela 3 traz dados referentes às variáveis sobre afastamentos, além do uso de medicamentos e doenças dos motoristas entrevistados. Como observado, praticamente $1 / 3$ dos entrevistados $(28,60 \%)$ fazem uso de medicamentos indicados para hipertensão e diabetes. Por sua vez, $71,40 \%$ da totalidade dos motoristas que responderam ao questionário afirmam possuir algum tipo de doença após o início das atividades no transporte público, como enxaqueca, colesterol alto, hipertensão, diabetes e doenças na coluna.

Tabela 3 - Variáveis sobre afastamentos e diagnósticos de doenças, $\mathrm{N}=7$.

\begin{tabular}{lll}
\hline Características & $\mathbf{N}$ & $\%$ \\
\hline Afastamento por doença & & \\
\hline Sim (COVID, apendicite, acidente) & 03 & $42,90 \%$ \\
Não & 04 & $57,10 \%$ \\
\hline Uso de medicamentos & & \\
\hline Sim (hipertensão e diabetes) & 02 & $28,60 \%$ \\
Não & 05 & $71,40 \%$ \\
\hline Diagnóstico de doenças & & \\
\hline Sim & 05 & $71,40 \%$ \\
Não & 02 & $28,60 \%$ \\
\hline
\end{tabular}

Fonte: Rêgo ACS, et al., 2021. 
Já a (Tabela 4) apresenta dados sobre a prevalência de distúrbios osteomusculares e a incapacidade funcional dos entrevistados. Nesse sentido observa-se que as regiões mais acometidas nos últimos 12 meses são: punho/mãos/dedos, seguido do cotovelo e joelho. Ressalta-se que a biomecânica exigida para a realização da atividade laboral dos motoristas causa sobrecarga nessas articulações, que em grande parte do dia ficam sobrecarregadas.

Tabela 4 - Prevalência de distúrbios osteomusculares e incapacidade funcional, N=7.

\begin{tabular}{ccccc}
\hline Região & $\begin{array}{c}\text { Sintomas nos } \\
\text { últimos 12 meses } \\
(\%)\end{array}$ & $\begin{array}{c}\text { Impedimento de } \\
\text { realizar atividades } \\
\text { normais por causa } \\
\text { deste problema nos } \\
\text { últimos 12 meses (\%) }\end{array}$ & $\begin{array}{c}\text { Nos últimos 12 } \\
\text { meses, } \\
\text { consultou } \\
\text { algum } \\
\text { profissional da } \\
\text { saúde (\%) }\end{array}$ & $\begin{array}{c}\text { Sintomas } \\
\text { nos últimos } \\
\mathbf{7} \text { dias } \\
(\%)\end{array}$ \\
\hline Pescoço/Região cervical & $14,30 \%$ & - & - & - \\
Ombros & $14,30 \%$ & - & - & $14,30 \%$ \\
Região Dorsal & - & - & $14,30 \%$ & $42,90 \%$ \\
Cotovelos & $57,10 \%$ & - & - & - \\
Punhos/Mãos/Dedos & $71,40 \%$ & - & - & $28,60 \%$ \\
Região lombar & $14,30 \%$ & - & - & $14,30 \%$ \\
Quadril/coxa & $14,30 \%$ & - & - & $14,30 \%$ \\
Joelhos & $42,90 \%$ & - & $14,30 \%$ & - \\
Tornozelos e pés & $14,30 \%$ & - & &
\end{tabular}

Fonte: Rêgo ACS, et al., 2021.

Como verificado através da Tabela 4, apesar de nenhum dos entrevistados ter relatado impedimentos para realização de atividades normais por conta de algum dos problemas citados, todos já sentiram ou sentem algum tipo de sintoma nas regiões citadas, dentre os quais é possível ressaltar que nos últimos doze meses, $71,40 \%$ dos entrevistados apresentaram algum tipo de sintoma nos punhos, mãos e dedos, $57,10 \%$ apresentaram sintomas nos cotovelos e $42,90 \%$ apresentaram sintomas nos joelhos.

Apesar dos incômodos, raramente os entrevistados buscam ajuda profissional, sendo possível constatar que nos últimos doze meses, apenas $14,30 \%$ destes procuraram algum tipo de ajuda especializada em regiões como a dorsal, tornozelos e pés.

\section{DISCUSSÃO}

Com a análise dos resultados obtidos, foi possível identificar sintomas osteomioarticulares nos motoristas de uma empresa de transporte público da cidade de Santarém-PA. Esses resultados foram capazes de demonstrar não somente a caracterização dos indivíduos entrevistados, mas também a forma como analisam as próprias condições de trabalho. Foi avaliado ainda o nível de cansaço dos participantes do final do expediente, bem como as condições do seu "ambiente de trabalho", especificamente se utilizam revestimentos nos assentos e se $o$ ajuste do banco é facilmente modificado.

Após a análise de dados, foi constatada prevalência de cansaço físico e mental na grande maioria dos entrevistados, onde os mesmos relataram sentir desconforto físico no desempenho de suas funções, apresentando dores osteomusculares em regiões como as costas, a cabeça e a lombar.

Esses problemas físicos são ocasionados pela junção de vários fatores, como o tempo de atuação na área, a alta temperatura em decorrência do clima da região, e, principalmente, a falta de exercícios físicos como forma de condicionar o corpo e as regiões mais afetadas pela jornada intensa de trabalho e suas variantes. Silva EBS, et al. (2015), afirma que as DORT's são condições multifatoriais, pois não são ocasionadas por um fator específico, mas sim pela associação entre fatores biomecânicos e agentes externos ou ambientais. 
Sobre as condições de trabalho dos motoristas de ônibus, Tavares FA (2011) entende que elas refletem diretamente na saúde física e mental do indivíduo, podendo ter consequências externas quanto ao relacionamento com demais pessoas. O mesmo autor, em pesquisa realizada com motoristas de ônibus no interior do Estado de São Paulo, constatou que as más condições de trabalho foram preponderantes para causar fadiga, irritabilidade e cansaço mental e físico.

É necessário observar que as condições de efetivação do processo saúde-doença estão inteiramente relacionadas ao ambiente físico no qual o indivíduo está inserido. No caso específico, os motoristas de ônibus cotidianamente se veem inseridos em um ambiente desordenado nas vias públicas, acidentes de trânsito, ruídos excessivos, estresse, elevada temperatura da região, longas jornadas de trabalho e salários que não condizem com a junção de todos esses fatores (SOUZA LPE, 2017).

De acordo com Kilesse R (2006) em pesquisa semelhante quanto às condições de trabalho dos motoristas de ônibus no interior do Estado de Minas Gerais, foi observado que o ambiente com calor excessivo, os ruídos e até mesmo o posicionamento dos motoristas na direção dos veículos, contribuíram para a formação de indivíduos hipertensos, diabéticos e com sobrepeso.

Pinto ABBH (2014), afirma também que o ambiente em que motoristas e cobradores de ônibus estão inseridos é um ambiente que necessita de muita concentração, pois facilmente podem se envolver em acidentes de trânsito. Porém ao mesmo tempo que precisa estar concentrado o mesmo está exposto à vários estímulos: ruídos, entrada e saída de passageiro, trânsito ao redor, entre outros, gerando como consequência um fator de extrema relevância nessa classe: o estresse.

Ainda de acordo com Tavares FA (2011), os motoristas de ônibus são indivíduos pertencentes a uma classe trabalhista que mais sofre com doenças ocupacionais, em comparação com outros profissionais, principalmente por deixar de trabalhar com média de idade menor que os demais profissionais em função dos problemas de saúde.

Ainda é possível acrescentar que a rotina de trabalho dos motoristas de ônibus leva ao desgaste físico e psicológico, uma vez que é necessária atenção constante ao trânsito e aos passageiros que desejam entrar ou sair do veículo. De acordo com Masson VA (2010), esses fatores são cruciais para o desenvolvimento de problemas como ansiedade e estresse.

Uma pesquisa realizada com motoristas de todo o país, relevou dados importantes sobre fatores relevantes para doenças ocupacionais. Nessa pesquisa foram abordados mais de mil motoristas de ônibus no estado, $57 \%$ deles afirmaram que dentre os pontos negativos dessa profissão estão: é uma profissão desgastante, estressante e cansativa fisicamente. Aproximadamente $20 \%$ dos entrevistados afirmaram que já necessitaram de atendimento médico após começarem a trabalhar. $E$ aproximadamente $30 \%$ deles solicitaram melhorias nos pontos de apoio aos motoristas, reforçando assim a necessidade de maior atenção a qualidade de vida desses funcionários (CNT, 2017).

Além da necessária atenção constante ao trabalho, o nível de exigência física e motora é crucial para a realização da condução do veículo, onde movimentos repetitivos com a cabeça, braços, ombros, membros inferiores e coluna vertebral em consonância com o sedentarismo, a médio e longo prazo, levam à problemas musculoesqueléticos (HOFFMANN MH, 2003). Em correlação com a presente pesquisa, $71,40 \%$ dos motoristas entrevistados relataram apresentar dores ao longo do corpo, como na lombar, cabeça e costas.

Em uma pesquisa realizadas com motoristas de ônibus no município de Belém - Pará, foi possível observar que os fatores que desencadeiam estresse e doenças ocupacionais na percepção dos motoristas são: calor, possibilidade de assalto, engarrafamento, trânsito desorganizado. Reforçando assim alguns fatores citados anteriormente que são comuns em muitas cidades brasileiras (DAMASCENO AFTB, 2019).

Em estudo semelhante realizado por Kilesse $R$ (2006), relatos de dores na coluna vertebral são constantemente relatadas por motoristas que trabalham por longos períodos, cujas reclamações são decorrentes do tempo prolongado em uma única posição, vibrações do veículo e repetidas movimentações de grupos musculares isolados. 
Ainda no que se refere às dores localizadas na coluna vertebral dos motoristas, é possível observar que as mesmas iniciam de forma branda, tornando-se intensas com o decorrer do tempo na relação duração de jornada versus período trabalhando na mesma função (SIMÕES MRL, et al., 2018). Nesse sentido, no presente levantamento foi constatado que $71,40 \%$ dos entrevistados apresentam algum tipo de dor na região lombar, costas ou cabeça, sendo que todos eles possuem, pelo menos, quatro anos de serviço corroborando com o estudo citado anteriormente.

Alcantara VCG, et al. (2020), analisa os riscos existentes nestes ambientes de trabalho, apenas de ser discutido em maior parte dos estudos sobre os riscos ergonômicos, o autor cita sobre os demais riscos existentes: como os riscos físicos, químicos, mecânicos e biológicos. Porém os ergonômicos ganham destaques pelas consequências que eles causam. Entre os exemplos pode-se ser citado sobre a falta de ajuste ergonômico nos bancos utilizados, que não permitem regulagem de altura, além da alta temperatura dentro dos veículos, somando-se aos prejuízos psicológicos esses aspectos influenciam de forma negativa na saúde dos motoristas.

Cavagioni LC, et al. (2009) entende que os problemas relacionados à saúde ocupacional dessa classe trabalhadora consistem numa complexa rede de fatores prejudiciais que são frequentes ao ambiente de trânsito, sendo possível destacar encontro com passageiros insatisfeitos, intercorrências e falhas mecânicas no veículo, exposição a ruído excessivo e vibrações constantes, temperaturas elevadas, dentre outros fatores capazes de ocasionar alterações físicas relativas a movimentos repetitivos e posturas viciosas durante a jornada de trabalho.

Pode-se verificar ainda na Tabela 1,71,4\% dos entrevistados apresentou cansaço físico e mental ocasionado por dores nas costas, na lombar e na cabeça. Para Carneiro LRV, et al. (2007), em motoristas, essas dores são causadas por movimentos repetitivos devidos à extensa realização de atividades como extensão de braços junto ao volante por várias horas, troca de marchas que envolve trabalho constante de ombros e pés, além da inércia constante das pernas por conta da exigência da posição sentada durante toda a jornada de trabalho.

Para Santos EAJ (2002), as dores que irradiam nas regiões cervical, lombar e dos membros superiores não estão somente relacionadas aos movimentos constantes necessários à prática das atividades cotidianas, ou a fatores ligados ao ambiente do trabalho, como movimentos bruscos (aceleração, frenagem, vibração), mas também a questões psicológicas que envolvem ansiedade e estresse. Simões MRL, et al. (2016), corrobora com os achados na sua pesquisa, onde $66,9 \%$ dos motoristas entrevistados apresentaram queixas álgicas no pescoço, ombro, braços e mãos.

Vários são os problemas decorrentes de atividades ocupacionais verificados em trabalhadores, principalmente os que, de alguma forma, necessitam do desenvolvimento de atividades repetitivas, jornadas longas e cansativas que afetam não somente o físico, mas também a sanidade mental do indivíduo (HOFFMANN MH, 2011). Na amostra pesquisada, foi observado tempo médio de vinte minutos para sete horas trabalhadas.

Não mais importante que os demais, mas excessivamente alarmante, o fato de $100 \%$ dos entrevistados afirmarem não praticar nenhum tipo de exercício físico (Tabela 2), é necessário ressaltar que o termo "exercício físico" não deve ser confundido com "atividade física", onde esta diz respeito à toda atividade corporal que exige movimentos, enquanto que àquele é referente às atividades realizadas de forma planejada no intuito de condicionar a aptidão física (SHIN C, et al., 2020)

De acordo com a Organização Mundial de Saúde, é recomendado, para adultos com mais de dezoito anos, no mínimo cento e cinquenta minutos de intensidade moderada de aeróbicos semanais (OMS, 2020). Apesar das recomendações, de acordo com estudo realizado por Masson VA (2010), quase metade dos motoristas que não realizam exercícios físicos de forma regular apresentaram doenças ocupacionais, sendo dados semelhantes aos que foram encontrados na amostra.

Além do tempo excessivo da rotina com movimentos repetitivos, ainda é necessário observar que alguns entrevistados possuem um longo tempo de trabalho, onde $28,60 \%$ dos indivíduos desenvolvem esse tipo de 
atividade há mais de quinze anos. Destaca-se o fato de que somente $14,30 \%$ dos indivíduos nunca sentiram qualquer sensação de vibração. De fato, este torna-se um dado alarmante tendo em vista que os efeitos da vibração podem causar enfraquecimento dos ossos em decorrência da perda de cálcio (SOUZA LPE, 2017).

No que se refere às vibrações excessivas, de acordo com Negreiros GMA (2016), é possível que, de acordo com a intensidade e duração, sejam detectados danos irreversíveis no indivíduo, iniciando com desconfortos e interferências nas atividades cotidianas, podendo evoluir para, em casos mais graves, perda de audição, alterações hormonais e doenças cardiovasculares.

Conforme pesquisa realizada por Lida L (2016), os motoristas de ônibus geralmente passam várias horas seguidas na frente do volante, não possuindo opções ou modos para mudar a postura, devendo permanecer sempre sentados, o que acaba levado a uma fadiga muscular e consequente enfraquecimento da atividade motora do indivíduo.

Como foi possível observar pela Tabela 4 pelo menos 14,30\% dos entrevistados acusaram alguns dos sintomas questionados, em regiões como pescoço, ombros, dorsal, cotovelos, punhos, mãos, dedos, lombar, quadril, coxa, joelhos, tornozelos e pés. Essa realidade é confirmada por Macedo CSG (2011) ao afirmar que dores que irradiam na região da coluna vertebral e até mesmo na região dos membros superiores são relatadas por motoristas que trabalham em tempo prologado, sendo ocasionada pelas rotações de tronco, vibrações e contração repetitiva de grupos musculares específicos.

Além dos fatores já citados anteriormente, um outro fator de risco tem crescido no último ano para atingir essa classe de trabalhadores, o risco de contaminação por COVID-19. A classe dos motoristas de ônibus está inserida na lista de serviços essenciais, assim como na lista de pessoas com maior chance de contaminação, podendo chegar à $71 \%$ de chance de contaminação (LIMA YO, et al. 2020). Somando-se assim mais um importante risco que afeta de forma negativa a saúde dos motoristas de ônibus.

\section{CONCLUSÃO}

Considerando a relação entre os sintomas apresentados, as condições de trabalho e os demais fatores apresentados, bem como a relação destes com pesquisas semelhantes, é bastante provável que todos os aspectos apresentados estejam refletindo na saúde dos motoristas da cidade de Santarém-PA, principalmente em âmbito físico e psicológico. Sendo sugerida a implantação de políticas de prevenção aos malefícios das doenças ocupacionais, com a aplicação de medidas educativas no que se refere à postura e importância de condicionamento físico, realização de ginástica laboral de forma periódica, bem como melhores condições de trabalho que vão desde a melhoria estrutural dos veículos até a redução ou aumento das pausas no trabalho. A fim de reduzir os índices de Dort's encontrados, assim como prevenir a evolução dessas doenças, e melhorar a qualidade de vida desses trabalhadores.

\section{REFERÊNCIAS}

1. ALCANTARA VCG, et al. Traffic in the understanding of bus drivers: possibilities of interdisciplinary care. Research, Society and Development, 2020; 9(3).

2. BORDALO AA. A iniciação científica. Rev. Para. Med., 2006; 20(2).

3. CARNEIRO LRV, et al. Sintomas de distúrbios osteomioarticulares em motoristas e cobradores de ônibus. Rev. Bras. de Cineantropom. Desempenho Humano, 2007; 17-23.

4. CAVAGIONI LC, et al. Health problems, hypertension and predisposition to stress in truck drivers. Revista da Escola de Enfermagem da USP, 2009; 43(SPE2): 28-45.

5. CONFEDERAÇÃO NACIONAL DO TRANSPORTE (CNT). Perfil dos Motoristas de Ônibus Urbanos. Brasília - DF, 2017; $114 \mathrm{p}$.

6. DAMASCENO AFTB. Estresse ocupacional dos motoristas e cobradores de ônibus da rmb. estudo de caso: Linhas que têm o final da rota no terminal rodoviário da Universidade Federal do Pará. Trabalho de Conclusão de Curso Universidade Federal do Pará, 2019.

7. DOSEA GS, et al. Sintomatologia osteomuscular e qualidade de vida de portadores de distúrbios osteomusculares relacionados ao trabalho. Escola Anna Nery, 2016; 20(4): 1-9.

8. FIGUEIREDO MAM, et al. Transporte coletivo: Vibração de corpo inteiro e conforto de passageiros, motoristas e cobradores. Journal of Transport Literature, 2016. 
9. HOFFMANN MH. Condições de trabalho e saúde de motoristas de transporte coletivo urbano. Estudos Psicologia, 2011; 120p.

10. KILESSE R. Avaliação de fatores ergonômicos em psotos de trabalho de motoristas de caminhões utilizados no meio agrícola. Engenharia na agricultura, 2006; 35-49.

11. KNECHTEL MR. Metodologia de pesquisa em educação: uma abordagem teórico-prática dialogada. Curitiba: Intersaberes, 2014.

12. LIDA L. Ergonomia: Projeto e Produção. 3. Ed. São Paulo. Blucher, 2016; 260p.

13. LIMA YO, et al. Risco de Contágio por Atividade Essencial no Brasil. Impacto COVID-19, 2020.

14. MACEDO CSG. Impacto da lombalgia na qualidade de vida de motoristas de ônibus urbanos. Revista Unopar, 2011; 9-15.

15. MASSON VA. Estilo de vida, aspectos de saúde e trabalho de motoristas de caminhão. Revista Brasileira de Enfermagem, 2010; 64; 16-22.

16. MEDEIROS UV, SEGATTO GG. Lesões por Esforço Repetitivo (LER) e distúrbios osteomusculares (DORT) em dentistas. Rev. Bras. Odontologia, 2012; 69(1).

17. MORAES PWT, BASTOS AVB. Os Sintomas de LER/DORT: um Estudo Comparativo entre Bancários com e sem Diagnóstico. Psicologia: Ciência e Profissão, 2017; 37(3): 624-637.

18. NEGREIROS GMA. Estudo das vibrações induzidas ao corpo humano causados por ciclismo outdoor - Experimento e modelagem. Centro Federal de Educação Técnológica Celso Suckow da Fonseca, 2016.

19. ORGANIZAÇÃO MUNDIAL DA SAÚDE (OMS). OMS lança novas Diretrizes sobre atividade física e comportamento sedentário, 2020. Disponível em: https://www.paho.org/pt/noticias/26-11-2020-oms-lanca-novas-diretrizes-sobreatividade-fisica-e-comportamento-sedentario. Acesso em 10 Jan. 2021.

20. PINTO ABBH. Condições de Trabalho do Motorista e Cobrador de Ônibus Urbano de Passageiros na Região Metropolitana do Recife: Proposta de Material para Capacitação. Dissertação (Mestrado em Design) - Centro de Artes e Comunicação, Universidade Federal de Pernambuco, Recife, 2014; 192.

21. RIBEIRO HP. A violência oculta do trabalho: as lesões por esforços repetitivos. Revista Fiocruz, $1999 ; 22-21$.

22. SANTOS EAJ. Do que adoecem e morrem os motoristas de ônibus? Uma revisão de literature. Rev. Bras. Med. Trab., 2002; 16-30.

23. SHINN C, et al. Programa Nacional para a Promoção da Atividade Física: o caso de Portugal. Ciênc. saúde coletiva, 2020; 25 (4).

24. SILVA EBS, et al. Análise funcional com enfoque físico de membros superiores em professores com síndrome dolorosa. Revista Cadernos Brasileiros de Terapia Ocupacional, 2015; 23(4): 757-764.

25. SIMOES MRL, et al. Dor musculoesquelética em motoristas e cobradores de ônibus da Região Metropolitana de Belo Horizonte, Brasil. Ciência \& Saúde Coletiva, 2018; 23(5): 1363-1374.

26. SOUZA LPE. Prevalência e fatores associados à hipertensão em trabalhadores do transporte coletivo urbando no Brasil. Revista Brasileira de Medicina do Trabalho, 2017; 16: 52-59.

27. TAVARES FA. Estresse em motoristas de transporte coletivo urbano por ônibus. Disponível em: htpp://www.webposgrad.propp.ufu.br. Acesso em 3 Jan. 2021.

28. ULHOA MA. Distúrbios psíquicos e condições de trabalho em motoristas de caminhão. Revista Saúde Pública, 2010. 